\title{
Sociotechnical Systems for High Rise Detention
}

\author{
Hugh D. LESTER ${ }^{\mathrm{a}, 1}$, Graham B. McKAY ${ }^{\mathrm{b}}$ and Ellyn A. LESTER ${ }^{\mathrm{c}}$ \\ ${ }^{a}$ Urbahn Architects, PLL, USA \\ ${ }^{\mathrm{b}}$ University of Sharjah, United Arab Emirates \\ ${ }^{\mathrm{c}}$ Stevens Institute of Technology, USA
}

\begin{abstract}
Society deems detention facilities successful when total life cycle cost is minimized without compromising safe, secure, and constitutional incapacitation. However, this consensus view represents only a minor subset of the potential of jails. System boundaries should be expanded, and a much larger set of outcomes considered. This case study of the design of a high-rise jail embodies transdisciplinary exploration of operational integration, architectural design, and engineering disciplines. The resulting 1,200-bed facility will rise 193.5 feet (59 meters) and cost an estimated $\$ 1.4$ billion dollars. Sociotechnical systems ultimately determine conditions of confinement and the successful administration of justice within facilities that incarcerate. While organizational and detainee culture contribute to the criminogenic | rehabilitative continuum of outcomes, design can rise to the level of organizational culture, psychological drivers, and policies, procedures, and post orders in its potential to influence outcomes. Justice facilities are complex adaptive systems that cannot be directly controlled. We can - at bestinfluence their evolution, nudging them toward desired goal states.
\end{abstract}

Keywords. Operational Integration, Organizational Culture, Sociotechnical Systems, Justice Facilities, High-rise Jail

\section{Introduction}

The policy of the City of New York is to replace their existing jail system with a new borough-based jail system, allowing the existing jails on Rikers Island to be decomissioned and demolished. Towards this end, a Culture Change Working Group within the Mayor's Office of Criminal Justice (MOCJ) Justice Implementation Task Force is pushing for those incarcerated to have access to stabilizing services, effective programming, and re-entry support. They are also pressing for supports and professional development opportunities so correctional officers and staff can serve the public with integrity. Finally, they are seeking "...the best ways to improve safety and opportunity for people inside the jails and design modern jail facilities." [1]

The goal of "...a jail system in which all who spend time in the City's jails including DOC employees, medical staff, service providers, incarcerated people, volunteers, and visitors - interact in a safe and respectful environment" [2] is clear, but the means to achieving it are not. The challenges are daunting, based on the existing organizational culture at the Department of Correction. Testimony from Kandra Clark, a former detainee on Rikers Island, illustrates them.

\footnotetext{
${ }^{1}$ Corresponding Author, Email: lesterh@urbahn.com.
} 
Each and every night I spent on Rikers I was fearful for my life and my body. It was not the other women I was incarcerated with that I feared. For me, it was the male correctional officers who would watch me go to the bathroom through the window in my cell door each night. Or the officers that would use their flashlights to watch me for several minutes while I tried to cover my body and lay underneath a sheet sweating in a nearly 100 degree cell the size of a closet. It was the feeling of being trapped, knowing that if I covered the window in my cell door with a piece of paper for even a second of privacy, I would receive a ticket and be sent to solitary confinement. It was the paralyzing fear of going to solitary confinement at an officer's whim, an unimaginable torture that I knew I could not handle. It was the constant exposure to derogatory and sexist comments, harassing remarks, and abusive language that fueled the demeaning environment on a daily basis. It was the absolute power that correctional officers, particularly male officers, held over me, and the fact that there was no one for me to report abuse/neglect to. [3]

Department of Correction officers are responsible for the care and custody of detainees, yet can use their positions to abuse, with little or no recourse. Policies against sexual harassment and abuse are in place, but they mean very little when the department fails to enforce them. From 2013 to 2015, serious complaints - such as allegations of assault, sexual assault, and complaints about staff - more than doubled. [4] Such trends raise serious concerns that the prevailing culture will transfer to replacement jails in different locations, no matter how they are designed.

\section{Interventions Proposed by MOCJ / Culture Change Working Group}

The strategy is to prevent recidivism by

1. Offering everyone in city custody 5 hours per day of education, vocational, and therapeutic programming,

2. Offering everyone in city custody dedicated re-entry planning before discharge and support in the community via a re-entry network and jails to jobs program, and by

3. Implementing a case management system. [2]

Further, establish high-level, aspirational objectives for programming that

4. Inspire hope in an institutional environment by encouraging positive thinking and a prosocial mindset,

5. Respond to an individual's current and emerging needs over time,

6. Provide opportunities to reduce the use of punitive practices in jails, and

7. Address the root cause or issue that led a person to jail. [5]

Finally, by leveraging designs

8. that facilitate opportunities for group and individual programming,

9. that provide ease of access to and from programming spaces, and

10. that meet the demand for a variety of programming spaces, including

a. adequate separation,

b. proximity to housing areas (to reduce the need for movement), and

c. some spaces far away from housing areas, [5]

barriers to participation are mitigated. 


\section{Sociotechnical Systems in Justice Systems and Facilities}

Justice facilities are complex adaptive systems (see Figure 1).

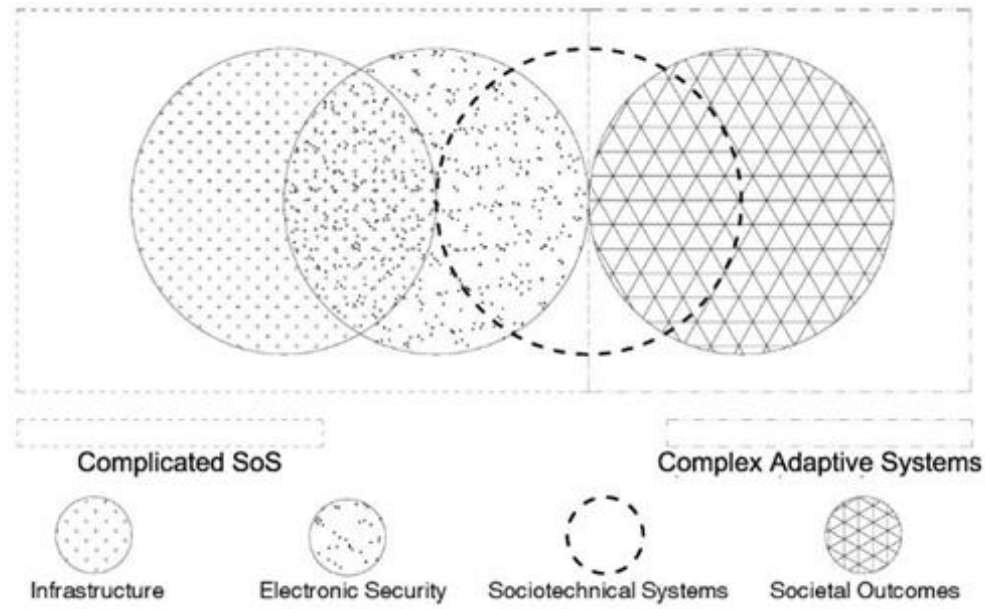

Figure 1. Justice facilities systems diagram.

Where justice facilities are concerned, complicated systems of systems (SoS) encompass "bricks and mortar" elements such as physical barriers, secured openings, and other elements that are durable and relatively difficult to change. These we designate as "infrastructure." Complicated SoS also encompass electronic security systems, which are now almost increasingly digital, networked internet protocol (IP) addressable devices along with the software which drives programmable logic controller (PLC) based industrial controls that remotely operate locks or relay the activity of sensors. [6] The overlap between the infrastructure set and the electronic security set represents the physical elements that conduct the digital signals that the software interprets in order to sense, or produces in order to control. These are infrastructure, but are inert without the software that represents the balance of the electronic security set.

Sociotechnical systems bridge between complicated SoS and complex adaptive systems (CAS). This is where individual agents - the human beings that staff the jail, and those detained within in-reside in the system. The sociotechnical systems set is tangent to the infrastructure set at the touch screen human-computer interface (HCI) of the control system, as well as at manual interfaces for doors and other elements that can be manipulated, such as door hardware. The half of the sociotechnical systems set that falls within complicated SoS encompasses each individual's interactions with the physical and virtual environment, across all sensory modalities. The other half of the sociotechnical systems set falls within CAS, on the other hand, and represents all personto-person or person-to-group interactions and associated dynamics.

Complex Adaptive Systems - defined as a complex, self-similar collectivity of interacting, adaptive agents [7] - often produce unforeseen consequences. This is due to emergent behaviors typical of large numbers of autonomous agents attempting to maximize their own outcomes within the reality they collectively construct. 'Sociability' is one way to characterize this dynamic, in which "aggregate outcomes emerge not from an act of collective decision-making, but through the accumulation of decentralized, individual decisions that, taken together, nonetheless conduce to a circumstance that 
affects the entire group." [8] Sociability, in the context of a jail, encompasses the organizational culture of the custody staff, as well as detainee culture so intimately described by Goffman. [9] Although policies, procedures, and post orders signpost the intended organizational culture, organic development based on buy-in at all levels - or the lack thereof - continuously drives the evolution of organizational culture. Due to the fragility of organizational culture and all correctional successes for that matter, Wener [10] warns that the task of maintaining organizational culture never ends.

In the final set-societal outcomes- the overlap between sociotechnical systems and societal outcomes represents the policy realm. The balance of the set represents aggregate outcomes that accrue from the individual decisions made by agents under the influence of externalities. These decisions generate networked systems and their outcomes, such as employment rates, market fluctuations, economies, public health, work environments, rates of mental illness, and justice system metrics such as recidivism (rates of reoffending and reincarceration,) rates of sexual harrasment or abuse, and levels of compliance during post-release supervision for sentenced inmates.

While complexity can't be managed with any certainty or precision, we can manage engineered systems that are complicated. Our task in this paper is to identify the complicated SoS levers that may be able to steer the complex adaptive system that is a high-rise jail towards positive societal outcomes. These levers would fine-tune the complicated while nudging CAS toward desired outcomes, with the goal of sustainable, safe, secure, and constitutional pre-trial detention in dense urban settings.

\section{The Design of a High-rise Jail}

This case study of the design of a high-rise jail is predicated on publicly available information from the City Environmental Quality Review (CEQR) for the borough-based jail system in New York City. [11] Four sites were identified. Each was to host a 1,500bed jail. This has since been reduced by 300 beds per facility due to legislation passed by the State of New York eliminating cash bail. The podium or base at each site varies due to site constraints and variations in program. For example, the Queens site will host the female beds for the entire system, along with associated services such as a maternity ward and other gender specific services, due to its larger footprint and maximum zoning envelope. Housing represents the opportunity for a standardized approach at all four sites. Standardized housing units and housing support would be a boon to jail operations, since line staff would only need to train on one type (layout) of mini-jail, systemwide.

Housing must be subdivided in detention facilities in order to maintain appropriate span of control. [12] In a high-rise configuration, efficiency of vertical circulation and minimization of detainee movement is synonomous with the "mini-jail" concept developed by Frank Repas of Gruzen and Samton in 1979 [13]. The project he was working on, the future Manhattan Detention Center (MDC) South Tower, was originally designed by Corbett and Meyers in 1938 but was shuttered in 1974 due to the need for a complete renovation. Since adding elevator shafts on the exterior of the building was to be avoided, and existing elevator capacity was insufficient, Repas' concept reduced the number of elevator stops, allowing higher throughput within the existing elevator infrastructure. This also subdivided the housing and housing support in alignment with detainee classification and proposed operations. The resulting reconfiguration was a direct supervision facility (see Figure 2) that was part of “...the greatest turnaround in jail safety this or any correctional agency has ever accomplished." [14] 
How many beds are appropriate per mini-jail? The heuristic for span of control calls for approximately 300 detainees, based on balancing effective supervisory staffing and resulting operational costs. Jail staffing is "more art than science," [12] so this heuristic is contingent on specifics - especially the layout of the facility.

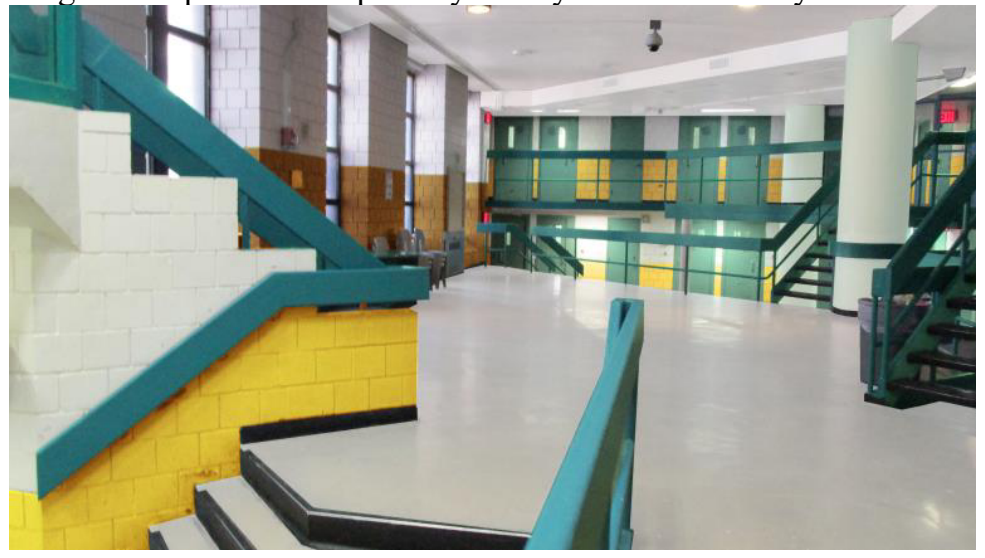

Figure 2. Direct supervision unit at MDC South Tower [15].

Dividing the 1,200 beds by four results in 300 detainees per mini-jail. Subdividing those 300 beds into five housing units results in 60-bed housing units, which falls within the American Correctional Association (ACA) recommendation of 64 or fewer beds per unit. It is worth noting that Hillsborough County, Florida has committed custody stafff who have safely operated well-designed 72-bed units at the Falkenburg Road Jail for decades. Additionally, proper objective classification tends to supress the census, as long as the facility is not overcrowded. Significantly, the emphasis on extensive programming in the borough-based jail system [MOCJ Intervention Strategy 1.] means that the actual and apparent density of the housing units will be lowered during waking hours, when programming is offered. Assuming that a maximum of 12 one hour slots of programming per day can be scheduled, the 52 detainees $^{2}$ will be distributed as 30 detainees in the dayroom or adjacent indoor recreation and 22 detainees in proximate programming spaces within the mini-jail units, or the larger facility, not counting visits to the medical clinic and other reasons detainees might be off unit. Outside of designated meal and hygiene periods, only half of the rated capacity will be present at any one time.

\section{Relative NSF for Activities}

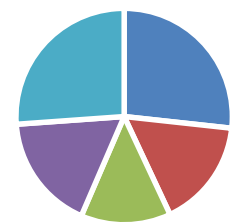

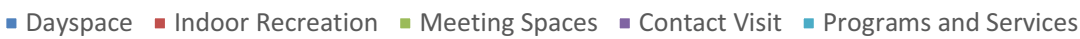

Figure 3. Distribution of Activity Space in each Mini-Jail Housing Unit.

${ }^{2}$ 60-bed capacity reduced by classification, peaking, and maintenance factors 
The design of the standardized housing unit is best understood by explaining the relative amount of activity space provided (See Figure 3). The dayspace for 60 detainees is 2,161 net square feet (NSF) or $26.7 \%$ of activity space. This is an efficient $61 \mathrm{NSF}$ more than American Correctional Association Local Adult Detention Facility requirement. Meeting space on the unit is for small groups and interviews. It totals 1,088 $\mathrm{NSF}$, or $13.5 \%$ of activity space. Indoor recreation is $1,318 \mathrm{NSF}$, or $16.3 \%$ of activity space. While this exceeds regulatory minimums, it also allows true half court basketball, the best option for large muscle exercise. Contact visitation space is $1,405 \mathrm{NSF}$, or $17.4 \%$ of activity space. This generous proportion is based upon the potential size of a detainee's family, including children. If eight detainees visit simultaneously, each could have an average of four visitors without crowding. Contact visit of this size will support peak demand while allowing multiple visits per week. Finally, program and services space constitute $2,113 \mathrm{NSF}$, or $26.1 \%$ of activity space. This generous allocation reflects the primacy of this use to the mission of the facility. Each detainee ${ }^{3}$ is allocated $134.75 \mathrm{NSF}$ of shared activity space within their mini-jail, a figure that significantly exceeds justice facility programming norms [16].

Next, incorporating space for building systems while facilitating maintenance access is critical. Perkins-Eastman, masterplanner of the Boroughbased Jail (BBJ) System, proposes mechanical or plant space in a (rooftop) penthouse and in the top floor of the podium (see Figure 4). This approach conforms to standard, high-rise centralized systems design, which locates service floors based on static pressure limits of pipework systems. [18] Fifteen floors can be served from a single service floor in standard commercial construction. [19]

The proposed design takes a different approach,

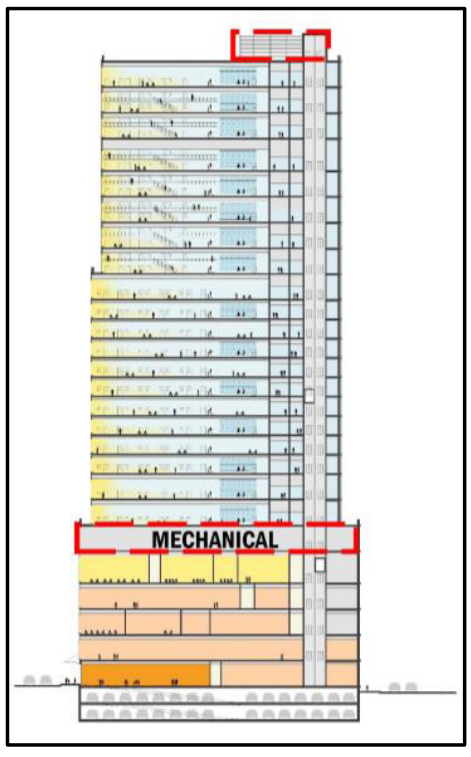

Figure 4. Plant floors [17]. that of semi-decentralized systems on interstitial - maintenance staff only-half-height service floors between mini-jails. The five air handlers would be slightly oversized and would supply distribution ductwork configured in a ring for redundancy. Four of the five are sufficient to supply all five housing units in a mini-jail, allowing one to be offline for maintenance or replacement without impacting operations. Redundancy of this type is not practical within the approach indicated in the master plan, especially within the constrained floor-to-floor heights typical of that approach.

When supply is ducted and the cell chase acts as the return air plenum, serving too many stacked cells and floors necessitates increases in cell chase size, impacting layouts. In addition, when a waste line is blocked, all the cells above the blockage will be impacted. Without frequent service floors with sanitary cleanouts, it becomes more difficult to locate and clear such blockages. Maintenance personnel must enter dayrooms

3 Rated capacity, not actual capacity reflecting classification, peaking and maintenance factors 
to both diagnose and clear the blockage, necessitating lockdowns in stacked units, significantly impacting operations.

This case study explores the tradeoffs associated with the design of housing towers in a high-rise jail. The additional choices that follow flesh out the complicated SoS that form the backdrop for sociotechnical systems in the complex adaptive system of the highrise jail.

\section{Transdisciplinary Engineering}

Few design disciplines are more interdisciplinary in nature than jail/prison design. The three building types considered the most complex and challenging for interdisciplinary teams are laboratories, jails/prisons, and hospitals, in that order. In terms of building systems, the ranking is laboratories, hospitals, then jails/prisons. In terms of user challenges, it is jails/prisons, laboratories, then hospitals. In no other building type are the users (detainees) actively and continuously attempting to circumvent, disrupt, and/or defeat both physical and electronic security systems and normal facility operations. Jails must keep bad actors in, and bad actors and contraband out. Safe, secure, and constitutional detention involves keeping the public safe from detainees, keeping detainees safe from other detainees, keeping staff safe from detainees, and notably, keeping detainees safe from staff. The only real truism in justice facility design is "if $\underline{i t}$

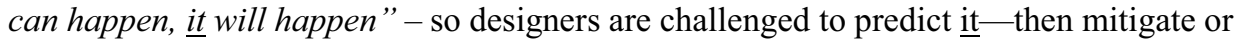
prevent it from happening through design and operational integration.

While the sociological foundation of corrections is organizational culture, core psychological factors driving outcomes [20] are:

1) Fear: staff vigilance in response to personal risk

2) Stress: staff and detainee stress levels, regardless of predicates

3) Fatigue: improved brain chemistry, post exercise

In direct supervision, staff vigilance is assured. Anything less than complete situational awareness and proactive engagement with detainees will increase the chance of detainee-on-staff assaults. To avoid staff vigilance escalating to hypervigilance, complicated SoS in the jail must support operations-lowering staff workload and uncertainty.

Conversely, detainees keep direct supervision officers under counter-surveillance, dampening nonfeasance, misfeasance, malfeasance, and connivance, especially when means of reporting allegations are available and effective. [21] In NYC jails, detainees can dial 311 from free inmate phones with complaints. [22] A separate system is available to report Prison Rape Elimination Act of 2003 (PREA) allegations. [23] Their effectiveness, however, is a matter of some concern. [22,23]

Real-time staff and detainee brain chemistry reflect levels of stress, aggression, and fatigue which either trigger or mitigate negative behaviors. Following large muscle exercise, levels of psychological and physiological arousal are lowered, mitigating stress or the potential for aggressive behavior. Locating indoor recreation half court basketball at each unit adjacent to the dayroom facilitates unfettered access.

In order for the jail's complicated SoS to robustly support operations, the electronic security system needs to be fully integrated with physical barriers, remotely operated doors, and standing operational procedures. Further, the jail management system, [24] case management system, [25] and learning management system must be fully integrated with the above. 


\title{
What does this mean in terms of transdisciplinary engineering?
}

One, the architect must design spaces without blindspots to support optimal (counter)surveillance. Spaces designed for movement, especially unescorted movement, should ideally be transversible by a single person at a time. This applies to mezzanine walkways, stairtowers, and elevators in this case study. Program and support spaces must be accessed based on scheduled use, and all shared spaces will be directly supervised.

Two, the MEP, lighting, and acoustic engineers must design building systems to support effective vision, auditory perception, and human thermal comfort. The importance of quality detainee occupied spaces cannot be understated. When all these aspects of the design work well, and work well together, the building "gets out of the way" and the hard work of effective inmate supervision can proceed unfettered. [20]

Three, the security electronics engineer must design and specify a system that supports operations. This means an access control system that is sophisticated enough to minimize workloads for the controlling officer while ensuring secure operations. While the specifics of how this might be accomplished is beyond the scope of this paper, nontechnical details of notional operations and sequences of movement are described below.

Four, vendors for the various data management systems (jail management, case management, learning management, etc) must transcend disciplinary and platform boundaries to make these subsystems properly interface and share data. The operation and integration of all of these systems must be seamless and intuitive from the perspective of all participants functioning in their roles. Consider the following scenario:

\begin{abstract}
After waking up, showering, and getting dressed, Dante holds his bracelet up to the proximity reader mounted near his cell door, signalling his readiness for breakfast. The LED turns yellow, so he waits. Someone else must be on the mezzanine. The LED turns green, and the electromechanical lock cycles, allowing him to push the door open. Dante turns left and heads for the door at the end, presenting his bracelet for entry into the stairtower. This time the LED turns green immediately and the lock cycles, letting him pass. In anticipation of breakfast, he traverses the stairs quickly, once again presenting his bracelet at the door for the dayroom. The lock cycles, and he's in. There are already dozens of guys hanging out at the dayroom tables, but nobody has food trays. He looks for the C.O. and recognizes Rob, one of the younger guys who graduated from the academy last year. As he approaches, Rob reaches up to his lapel mounted radio and keys the mike, responding to some unheard query with some sort of code. "Say, Dante," Rob says, "the food cart is about to arrive. Could you go grab it, so we can get this started?" Dante nods, and heads for the main unit sallyport. He sees the utility officer rolling in the cambro carrier through the expanse of glass. He swipes out to the corridor so Dante's LED reads red, until the outer door's closer swings it shut and secure. Dante has to re-present his bracelet, and the lock cycles open. "Hold the door," he says to the nearest detainee, as he unplugs the cart and swings it around and into the dayroom. The cart station in the dayspace has a plug for the cart, and as he plugs it in, the guys start to cue up for breakfast. The food is piping hot, as is the coffee.
\end{abstract}

Later in the morning, his bracelet buzzes, and he swipes it at a kiosk with a touchscreen. Dante has a re-entry session upstairs in ten minutes. His schedule is full today. He also has a family visit at 11 am and outdoor recreation at 1:30am - a game between units $C$ and E of Mini-jail 3. Members of the winning squad will get two credits in their detainee accounts, losers one, and if there are any issues during the game, nobody gets any. Dante is two credits away from his favorite commissary item, which he goes ahead and orders on the kiosk in anticipation of the win. His bracelet vibrates again, and he heads for the stairtower door, goes through the door, up the stairs, and presents his bracelet at the door to 'Search,' the sallyport that leads to the Programs and Services corridor. The search room is empty, and the LED on the second door shows yellow. Wait. 


\begin{abstract}
On the other side of the door, the escort officer approaches the door from down the corridor. The lantern above the door lit and sounded a chime, prompting his approach. On the door, an integrated flat screen shows a picture of Dante with his name superimposed and "Suite 5 Re-entry Planning" underneath. Swiping the door open, the escort officer says, "Dante, welcome. Suite 5 for re-entry. Red door on the left, just past the vending area." Dante heads that way, looking at the vending machines on the right through the glazing, reminded of this afternoon's game. He swipes the red door and enters, never even looking back at his escort, who he didn't recognize. He sits down in a waiting area, and picks up a magazine. Somebody needs to refill the empty five gallon bottle on the cooler. He wonders if he'll get the same social worker as last time. The magazine is lame, but he knows his bracelet will let him know when she's ready, so he settles in and gives the magazine his full attention.
\end{abstract}

This scenario embodies the functional outcomes of transdisciplinary operational integration, architectural design, and engineering. Hopefully, this vision of a facility with seamless operations, a culture of respect, incentives to participation and pro-social behavior - and the technology to make it all possible - inspires possibilities for other sociotechnical systems applications. This 1,200-bed facility rising 193.5 feet (59 meters) and costing an estimated $\$ 1.4$ billion dollars will be worth it if Dante and other detainees, don't cycle back because their experiences while detained made things better, not worse.

\title{
5. Validation
}

An interview was conducted on May $23^{\text {rd }}, 2019$ from 9:30 - 11:30 am with Dr. Alethea Taylor, a member of the Culture Change Working Group of MOCJ's Justice Implementation Task Force, in order to validate the case study. The conceptual design was presented in depth, and Dr. Taylor took no exception to what was presented, other than to emphasize the need for careful use of terminology, such as 'detainee' versus 'inmate,' as well as to express a desire for evidence-based, gender-responsive, and trauma-informed design of all detainee accessible spaces in the new jail system.

\section{Conclusion}

Designers do not control public policy, legislation, judicial findings, or available funding. However, they can advocate for and design facilities that mitigate negative outcomes for everyone who becomes justice system involved. When design mitigates the potential for abuse and violence, and improves conditions of confinement, it blunts future negative outcomes no matter the other shortcomings of the justice system. When design supports operations, programming, and services, personal transformation is engendered. When complicated SoS levers are used to nudge complex adaptive systems like high-rise detention centers, societal outcomes are bolstered. Correctional design matters.

\section{References}

[1] E. Glazer, Progress on Closing Rikers Island, New York City Council's Committee on Fire and Criminal Justice Services, New York, NY, 2017.

[2] Mayor's Office of Criminal Justice, Justice Implementation Task Force Culture Change Working Group Meeting \#1 / November 8, 2017, New York, NY, 2017. 
[3] K. Clark, Testimony at the Oversight Hearing Examining Sexual Abuse and Harassment in City Jails, The New York City Council Committees on Criminal Justice and Women, New York, NY, 2018.

[4] Mayor's Office of Criminal Justice, Justice Implementation Task Force Culture Change Working Group Meeting \#2 Presentation / December 14, 2017, New York, NY, 2017

[5] Mayor's Office of Criminal Justice, Justice Implementation Task Force Culture Change Working Group Meeting \#4 Presentation / March 15, 2018, New York, NY, 2018.

[6] P.M. Keaty and H.D. Lester, Leveraging Emergent Security Technologies and Design: The New Kane County Adult Detention Center, Corrections Today, vol. 68, no. 6, 2006, pp. 30-31,36.

[7] Wikipedia, 2019, Complex Adaptive System, Accessed: 04.03.2019. [Online]. Available: https://en.wikipedia.org/wiki/Complex_adaptive_system

[8] D.S. Grewel, Network Power: The Social Dynamics of Globalization, Yale University Press, New Haven, CT, 2008.

[9] E. Goffman, Asylums: Essays on the Social Situations of Mental Patients and Other Inmates. Doubleday (Anchor), Oxford, England, 1961.

[10] R.E. Wener, The Environmental Psychology of Prisons and Jails: Creating Humane Spaces in Secure Settings, Cambridge University Press, New York, NY, 2012.

[11] NYC Department of Correction, 2018, CEQR 18DOC001Y Documents, Accessed: 15.08.2018. [Online]. Available: http://www.nyc.gov/18doc001y-borough-based-jail-system

[12] R.C. Miller, J.E. Wetzel, and J.M. Hart/CRS, Inc., Jail Staffing Analysis, $3^{\text {rd }}$ Edition, National Institute of Corrections, U.S. Department of Justice, Washington, D.C., 2016.

[13] D.M. Ziskind (Chief Architect, STV, Inc.), interviewed by H.D. Lester, New York, NY, December 2017, interviewer's hand notes.

[14] T. C. McCarthy/New York Correction History Society, 2019, MDC aka The Tombs is renamed the Bernard B. Kerik Complex, Accessed: 07.03.2019. [Online]. Available: http://www.correctionhistory.org/html/chronicl/nycdoc/html/bbkcomplex.html

[15] Urbahn Architects, PLLC C 2017

[16] J. Farbstein, Correctional Facility Planning and Design, $2^{\text {nd }}$ Edition, Van Nostrand Reinhold, New York, NY, 1986.

[17] Mayor's Office of Criminal Justice/Perkins-Eastman, 2019, NAC Meeting Materials-ManhattanMeeting 2-Presentation, Accessed: 25.02.2019. [Online]. Available: https://rikers.wpengine.com/wpcontent/uploads/Manhattan-NAC-Meeting-2.pdf

[18] A. Guthrie and R. Henderson, Servicing the Tall Building, In D. Parker and A. Wood (eds.): The Tall Buildings Reference Book, Routledge, New York, NY, pp. 311-328, 2013.

[19] N. Clark, Servicing and Energy, In N. Clark and B. Price (eds.): Tall Buildings: A Strategic Design Guide, $2^{\text {nd }}$ Edition, RIBA Publishing, Newcastle upon Tyne, UK, pp. 76-79, 2016.

[20] H.D. Lester, Psychological Drivers Influence Architectural Design: The Hinds County, Mississippi Penal Farm Replacement, In: PSYCON 2018, Wolverhampton, UK, 2018.

[21] NYC Board of Correction, 2018, Second Assessment of the New York City Department of Correction Inmate Grievance System, Accessed: 12.01.2018. [Online]. Available: http://alturl.com/44j3h

[22] R. McCray, NYC Inmates Call 311 To Report Mistreatment, But Is Anyone Listening?, Gothamist, 2018.

[23] NYC Department of Correction, 2016, Notice of Adoption of Rules [PREA], Accessed: 14.03.2019. [Online]. Available: http://alturl.com/f3h7m

[24] NYC Department of Correction, 2019, Report of the Finance Division on the Fiscal 2020 Preliminary Plan and the Fiscal 2019 Preliminary Mayor's Management Report for the Department of Correction, The Council of The City of New York, Accessed: 13.03.2019. [Online]. Available: http://alturl.com/9oc34, p. 30

[25] C. Brann/DOC, 2019, Video of Hearing of the Council of the City of New York Committee on Criminal Justice held 14.03.2019, Accessed 14.03.2019. [Online]. Available: $\underline{\text { http://alturl.com/n4ty6, timecode }}$ $1: 40: 53$ 